Fiji's Media Industry Development Authority (MIDA) chairman, Ashwin Raj, has raised concerns about alleged cases of 'hate speech' and statements calling for disorder and civil strife against the Fijian Government, on social media. According to Raj, hate speech and divisive materials on social media have been made in the name of democracy and those responsible for this are mainly youth (Vuibau $21 / 7 / 2015)$. In a similar vein, Fiji's cyber security unit, in the Ministry of Defence, has mentioned possibilities of limiting internet access due to the accessibility of pornographic sites which are linked to sexual crimes (Vuibau 17/7/2015).

This In Brief seeks to document the proposed plans for curtailing the 'excesses' of social media and challenges some of the ongoing claims related to social media. Additionally, it discusses some possible policy considerations for protecting freedom of speech in social media in Fiji and the wider Pacific.

\section{Social Media and Its 'Excesses' in Fiji}

Since the 2006 coup, heavy media censorship has contributed to the transition of discussions from traditional media to blogs to social media. While Fijis highly repressive media laws remain in place and have been criticised for their heavy penalties, to date they have largely focused on 'old' media: newspapers and radio stations. The prevailing media penalties have greatly restricted investigative journalism and have created an acquiescent media culture that is not free to ask questions that may challenge the Fijian Government.

In this climate, social media has become an alternative avenue for free speech and civic engagement. Facebook has become the most prominent social media platform in Fiji (Tarai et al. forthcoming), boasting 350,000 active account users as of July 2015. With a large percentage of the national population on Facebook, discussions have led to the formation and persistence of public discourse on national issues through
Facebook groups, such as Letters to the Editor Uncensored, Friends of Media Group and Fiji Democratic Forum.

The Fijian Government itself has used Facebook and Twitter to engage directly with the public. However, despite the widespread calls for feedback and public participation through social media regarding Fijis's flag change (Tarai et al. 2015), the police commissioner also warned the public to be careful when expressing sentiments on social media, citing cybersecurity and the fact that the police have the ability to obtain equipment necessary to identify members of the public (Vafo'ou 16/6/2015).

Facebook has come under increasing scrutiny by MIDA for the alleged abuses of freedom perpetrated through social media. These include claims that social media has been used in the luring of young girls by sexual predators (Sauvakacolo 17/7/2014), cyberbullying, harassment, discrimination and hate speech (Vuibau 21/7/2015). While these dangers give some cause for concern, more sexually related crimes are committed within communities and homes than through social media.

The chairman of MIDA is right in claiming that most social media users in Fiji are young people. Over 77 per cent of Fiji's Facebook users are 15-35 years of age. However, MIDA has provided no research or documentation to validate the claim that youths are to blame for 'divisive materials' and 'hate speech' online.

MIDA attacks on social media and young people form part of a new wave of attempts by government to deter expressive use of the media. While the government could control newspapers and radio by censorship or through media penalties, social media as a platform is much more difficult to curtail.

Threats and stigmatisation of users are ways to exert influence on forms of media that are technically difficult to control. Furthermore, blaming young people for unsubstantiated claims of social media abuse appears to provide the rationale for MIDA's proposed plans and policies. 


\section{'Unplugging' Social Media?}

At the 2015 Fiji multi-stakeholder security symposium, Raj announced that MIDA would be taking an 'epistemological' approach to curb the 'excesses' of social media. What this means is still vague, especially since MIDA's proposed plans have not materialised at the time of writing.

In an interview with Raj, a radio host suggested that social media might be 'unplugged' as a way of curtailing excesses. This was the first time that the suggestion of unplugging or blocking social media was brought to the fore of national discussions. In response, the MIDA chairman said he was wary of the possible international and internal condemnation that the Fijian Government could receive.

Indeed, the Fiji Government might consider the recent condemnation directed at the Nauru Government for its blocking of Facebook (Raines $5 / 5 / 2015$ ), but it also might be concerned about what sort of message such an action would send about its own commitments to democracy. The government claims to be Fijis's 'first genuine democracy' (Tunnicliffe 4/11/2013) and its political party, Fijifirst, relied heavily on social media in its 2014 election campaign.

If social media were to be 'unplugged' or stringently regulated, it would induce extensive international and internal condemnation against the Fijian Government, undermine its popularity and raise questions as to the legitimacy of the Fijifirst government's efforts in rebuilding democracy. Instead of 'unplugging' social media, Ashwin Raj revealed that MIDA was planning to train high school students on the use of social media, which we might see as an indirect technique for depoliticising social media expressions.

\section{Conclusion}

It seems that the authorities in Fiji are beginning to see the nation's thriving social media scene as something of a threat and may be moving to exert more control. This trend in Fiji is apparent elsewhere in the region, with the Nauruan ban on Facebook, moves in Solomon Islands to deregister the Facebook pressure group Forum Solomon Islands International (Galo 14/8/2015) and Papua New Guinea's discussions on social media laws (Pacific Freedom Forum 14/4/2015).

Instead of worrying about what is being expressed on social media, the Fiji Government ought to embrace the platform's open and transparent nature, and recognise that openness benefits the government. It can learn from its critics, whose activities, thoughts and actions are laid bare for all to see. Social media also allows for citizens to freely express their dissatisfaction and to provide checks on government power.

\section{Author Notes}

Jope Tarai is a graduate student and teaching assistant at the University of the South Pacific.

\section{References}

Galo, C-A., 14/8/2015. FSII Faces Deregistration. Island Sun.

Pacific Freedom Forum 14/4/2015. Social Media Law Could Chill Free Speech in Papua New Guinea. IFEX.

Raines, S. 5/5/2015. Nauru Facebook Ban Came 'at Request of Australian Government', Refugee Advocates Say. ABC News online.

Sauvakacolo, S. 17/7/2014. Predators Lure Young Girls Online. Fiji Times online.

Tarai, J., G. Finau, R. Kant and J. Titifanue 2015. Fiji Flag Change: Social Media Responds. SSGM In Brief 2015/42. Canberra: ANU.

Tarai, J., G. Finau, R. Kant and J. Titifanue forthcoming. Political Social Media Campaigning in Fijiss 2014 Elections. The Journal of Pacific Studies.

Tunnicliffe, B. 4/11/2013. First Democratic Election Claims in Fiji Rubbished. Radio New Zealand.

Vafo'ou, R. 16/6/2015. Fiji Police Warns Public to Monitor What They Express on Social Media Regarding the New Flag. FijiOne.

Vuibau, T. 17/7/2015. Porn Worry. Fiji Times online.

Vuibau, T. 21/7/2015. Education on Freedom of Speech Vital. Fiji Times online. 